\title{
Adsorption kinetics and thermodynamics of malachite green dye unto acid activated low cost carbon.
}

\section{HEMA M.; ARIVOLI S. *}

P.G. Department of Chemistry, M.R. Government Arts College,

Mannargudi 614 001, Tamilnadu, India.E-mail:arivu3636@yahoo.com

\begin{abstract}
A carbonaceous adsorbent prepared from an indigenous waste by acid treatment was tested for its efficiency in removing Malachite green (MG). The parameters studied include agitation time, initial dye concentration, carbon dose, $\mathrm{pH}$ and temperature. The adsorption followed first order reaction equation and the rate is mainly controlled by intra-particle diffusion. Freundlich and Langmuir isotherm models were applied to the equilibrium data. The adsorption capacity $\left(Q_{m}\right)$ obtained from the Langmuir isotherm plot were 9.7377, 9.6246, $9.6339,9.5693 \mathrm{mg} / \mathrm{g}$ respectively at an initial $\mathrm{pH}$ of 6.0 at $30,40,50$ and $60^{\circ} \mathrm{C}$. The temperature variation study showed that the Malachite green adsorption is endothermic and spontaneous with increased randomness at the solid solution interface. Significant effect on adsorption was observed on varying the $\mathrm{pH}$ of the Malachite green solutions. Almost $80 \%$ removal of Malachite green was observed at $60^{\circ} \mathrm{C}$. The type I and II isotherm obtained, positive $\triangle \mathrm{H}^{0}$ value, $\mathrm{pH}$ dependent results and desorption of dye in mineral acid suggest that the adsorption of Malachite green on PDC involves chemisorption as well as physisorption mechanism. @ JASEM
\end{abstract}

The discharge of highly coloured effluents into natural water bodies is not only aesthetically displeasing, but it also impedes light penetration, thus upsetting biological processes within a stream. In addition, many dyes are toxic to some organisms causing direct destruction of aquatic communities. Some dyes can cause allergic dermatitis, skin irrigation, cancer and mutation in man. Recent estimates indicate that, approximately, $12 \%$ of synthetic textile dyes used each year are lost during manufacture and processing operation and $20 \%$ of these dyes enter the environment through effluents that result from the treatment of residual industrial waters (Selvarani., 2000)

Wastewaters from dyeing industries are released in to nearby land or rivers without any treatment because the conventional treatment methods are not cost effective in the Indian context. Adsorption is one of the most effective methods and activated carbon is the preferred adsorbent widely employed to treat wastewater containing different classes of dyes, recognizing the economic drawback of commercial activated carbon. Many investigators have studied the feasibility of using inexpensive alternative materials like pearl millet husk, date pits, saw dust buffing dust of leather industry, coir pith, crude oil residue tropical grass, olive stone and almond shells, pine bark, wool waste, coconut shell etc., as carbonaceous precursors for the removal of dyes from water and wastewater (Singh and Tiwari.,2003: Sekaran et al.,1995) The present study was undertaken to evaluate the efficiency of a carbon adsorbent prepared from acid activated Pandanus carbon for removal of dye in aqueous solution. In order to design adsorption treatment systems, knowledge of kinetic and mass transfer processes is essential. In this paper, we have reported the applicability of kinetic and masstransfer models for the adsorption of Malachite green $(\mathrm{MG})$ onto activated carbon.

\section{MATERIALS AND METHODS}

\section{Materials}

Dried leaves of Pandanus were carbonized with concentrated sulphuric acid in the weight ratio of 1:1(W/V). The carbonization and activation was completed by heating for twelve hours in a furnace at $400^{\circ} \mathrm{C}$. The resulting was carbon washed with distilled water until a constant $\mathrm{pH}$ of the slurry was achieved. Then the carbon was dried for four hours at $100^{\circ} \mathrm{C}$ in a hot air oven. The dried material was grinded to a fine powder and sieved

All Chemicals used were of high purity, commercially available AnalaR grade. Stock solutions of $1000 \mathrm{mg} / \mathrm{L}$ of dyes were prepared using doubly distilled water.

\begin{abstract}
Methods
Malachite green (MG) dye stock solution was made up to a known concentration. From that solution $50 \mathrm{ml}$ of $5,10,15,20,25$ and $30 \mathrm{mg} / \mathrm{L}$ dye solutions were taken and to it was added $100 \mathrm{mg}$ of activated carbon adsorbent. These solutions were agitated at $30^{\circ}, 40^{\circ}, 50^{\circ}$, and $60^{\circ} \mathrm{C}$ in a defined time intervals, samples were withdrawn from the shaker and filtered. The solution was analyzed in an UVVisible spectrophotometer.

Desorption studies were carried out using the spent carbon. Carbon loaded with dyes was separated and gently washed with distilled water to remove any unasdsorbed dyes. The dye-laden carbons were agitated with $50 \mathrm{ml}$ each of water, $0.2 \mathrm{M}$ sulphuric acid, hydrochloric acid, and nitric acid and sodium chloride solutions separately for 30 minutes and analyzed for any dye content using UV-Visible spectrophotometer
\end{abstract}

\section{RESULTS AND DISCUSSIONS}

Effect of contact time and initial dye concentration

The experimental results of adsorptions of Malachite green (MG) dye on the activated carbon 
at various concentrations $(5,10,15,20,25$ and $30 \mathrm{mg} / \mathrm{L}$ ) with contact time are shown in Figure 1. The equilibrium data were collected in Table 1, reveals that, percent adsorption decreased with increase in initial dye concentration, but the actual amount of dye adsorbed per unit mass of carbon increased with increase in dye concentration. This means that the adsorption is highly dependent on initial concentration of the dye. It is because this that at lower concentration, the ratio of the initial number of dye molecules to the available surface area is low, subsequently the fractional adsorption becomes independent of initial concentration. However, at high concentration the available sites of adsorption becomes fewer and hence the percentage removal of dye is dependent upon initial concentration. Equilibrium was established at 40 minutes for all concentrations. Figure 1 reveals that the curves are single, smooth, and continuous, leading to saturation, suggesting the possible monolayer coverage of the dye on the carbon surface (Senthilkumar et al.,2005).

Table 1: Equilibrium parameters for the adsorption of Dyes onto activated Carbon

\begin{tabular}{|c|c|c|c|c|c|c|c|c|c|c|c|c|}
\hline \multirow[t]{3}{*}[D]{$_{0}$} & \multicolumn{4}{|c|}{$\mathrm{C}_{\mathrm{e}}(\mathrm{mg} / \mathrm{L})$} & \multicolumn{4}{|c|}{$Q_{\mathrm{e}}(\mathrm{mg} / \mathrm{g})$} & \multicolumn{4}{|c|}{ Dye removed (\%) } \\
\hline & \multicolumn{12}{|c|}{ Temperature ( C ) } \\
\hline & $30^{\circ}$ & $40^{\circ}$ & $50^{\circ}$ & $60^{\circ}$ & $30^{\circ}$ & $40^{\circ}$ & $50^{\circ}$ & $60^{\circ}$ & $30^{\circ}$ & $40^{\circ}$ & $50^{\circ}$ & $60^{\circ}$ \\
\hline \multicolumn{13}{|c|}{ MG adsorption } \\
\hline 5 & 1.4852 & 1.3456 & 1.2012 & 1.1015 & & & & & & & & \\
\hline & 35703 & 32527 & 3.316 & 32012 & 1.7574 & 1.8272 & 1.8994 & 1.9492 & 70.29 & 73.08 & 75.97 & 77.97 \\
\hline & & & & & 3.2100 & 3.2750 & 3.3442 & 3.3994 & 64.20 & 68.47 & 68.84 & 67.98 \\
\hline 15 & 6.1863 & 6.0137 & 5.9452 & 5.8124 & 4.4088 & 4.4934 & 4.5274 & 4.5938 & 58.78 & 59.91 & 60.36 & 61.25 \\
\hline 20 & 9.2245 & 9.0192 & 8.9921 & 8.7529 & 5.3877 & 5.4904 & 5,5039 & 56239 & 53.87 & 54.90 & 5503 & 56,23 \\
\hline 25 & 12.9348 & 12.8015 & 12.8015 & 12.5029 & 6.0326 & 6.0992 & 6.1937 & 6.2485 & 48.26 & 48.79 & 49.54 & 49.98 \\
\hline 30 & 16.4996 & 16.2856 & 16.1252 & 16.0021 & & & & & & & & \\
\hline & & & & & 6.7502 & 6.8572 & 6.9372 & 6.9989 & 45.00 & 45.71 & 46.24 & 46.65 \\
\hline
\end{tabular}

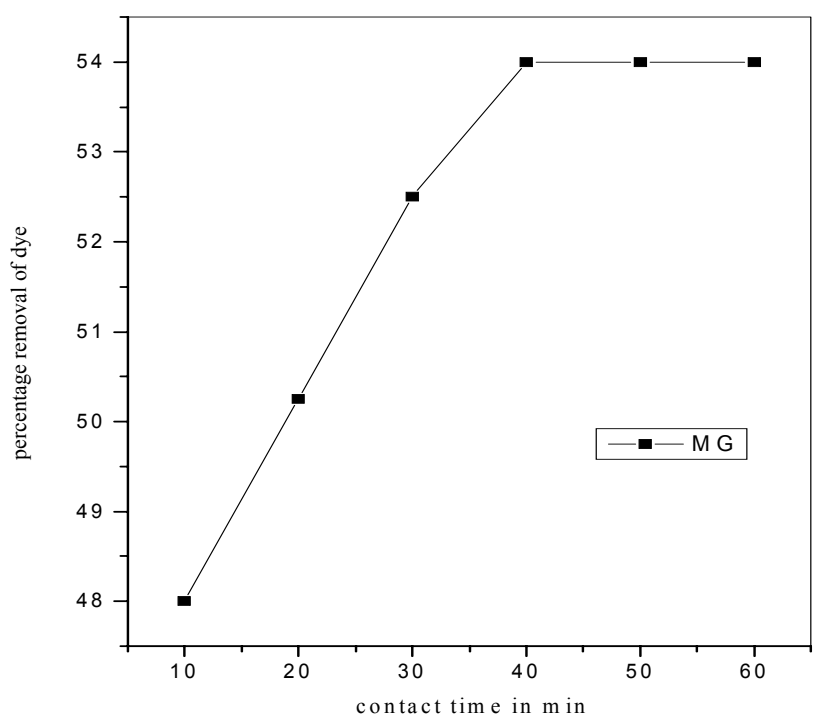

Figure. 1-Effect of contact time on the removal of dye by $P D C$

\section{Effect of carbon concentration}

The adsorption of the dye on carbon was studied by varying the carbon concentration $(50-250 \mathrm{mg} / 50 \mathrm{ml})$ for a fixed Malachite green (MG) concentration of $20 \mathrm{mg} / \mathrm{L}$. The percentage of adsorption increased with increase in the carbon concentration (Figure
2). This can be attributed to increased carbon surface area and availability of more adsorption sites (Vadivelan and Vasanthkumar., 2003) 
Table 2 : Langmuir isotherm results

\begin{tabular}{ccccc}
\hline Dye & Temp & \multicolumn{3}{c}{ statistical parameters/constants } \\
& ${ }^{0} \mathbf{C}$ & $\mathbf{r}^{2}$ & $\mathbf{Q}_{\mathbf{m}}$ & $\mathbf{B}$ \\
& & & & \\
$\mathbf{4}$ & & & & \\
& $\mathbf{3 0}$ & 0.9990 & 9.7377 & 0.1364 \\
& $\mathbf{4 0}$ & 0.9919 & 9.6246 & 0.1626 \\
& $\mathbf{5 0}$ & 0.9989 & 9.6339 & 0.1560 \\
& $\mathbf{6 0}$ & 0.9981 & 9.5693 & 0.1650 \\
& & & & \\
\hline
\end{tabular}

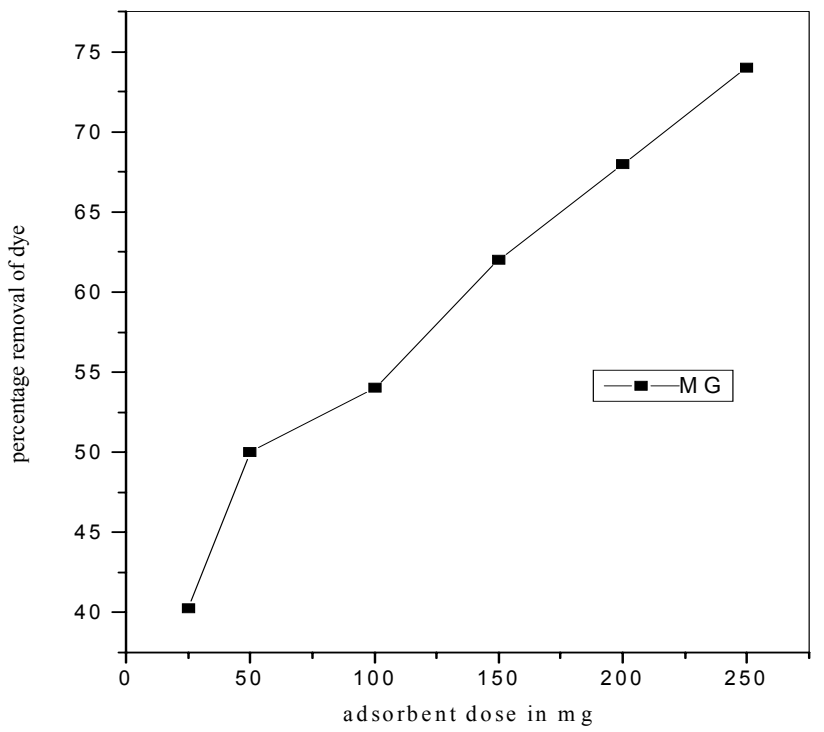

Figure. 2-Effect of dosage on the removal

of dye by PDC

Adsorption isotherm: The experimental data was analyzed according to the linear form of the Langmuir (Langmuir., 1918) and Freundlich (Freundlich., 1906) isotherms. The Langmuir isotherm represented by the following equation

$$
\mathrm{C}_{\mathrm{e}} / \mathrm{Q}_{\mathrm{e}}=1 / \mathrm{Q}_{\mathrm{m}} \mathrm{b}+\mathrm{C}_{\mathrm{e}} / \mathrm{Q}_{\mathrm{m}}
$$

Where $\mathrm{C}_{\mathrm{e}}$ is the equilibrium concentration $(\mathrm{mg} / \mathrm{L})$, $\mathrm{Q}_{\mathrm{e}}$ is the amount adsorbed at equilibrium $(\mathrm{mg} / \mathrm{g})$ and $\mathrm{Q}_{\mathrm{m}}$ and $\mathrm{b}$ are Langmuir constants related to adsorption efficiency and energy of adsorption, respectively. The linear plots of $\mathrm{C}_{e} / \mathrm{Q}_{\mathrm{e}}$ versus $\mathrm{C}_{\mathrm{e}}$ suggest the applicability of the Langmuir isotherms. The values of $\mathrm{Q}_{\mathrm{m}}$ and $\mathrm{b}$ were determined from slope and intercepts of the plots and are presented in Table 2. From the results, it is clear that the value of adsorption efficiency, $Q_{m}$ and adsorption energy, $\mathrm{b}$ of the carbon increases on increasing the temperature. From these values we can conclude that the maximum adsorption corresponds to a saturated monolayer of adsorbate molecules on adsorbent surface with constant energy and there was no transmission of adsorbate in the plane of the adsorbent surface. The trend shows that the adsorbent prefers to bind acidic ions and that speciation predominates on sorbent characteristics, when ion exchange is the predominant mechanism. Further, it confirms the endothermic nature of the processes involved in the system (Krishna and Bhattacharrya., 2002) To confirm the favourability of the adsorption process, the separation factor $\left(R_{L}\right)$ was calculated and presented in Table 4. The values were found to be between 0 and 1 and confirm that the ongoing adsorption process is favourable (Senthilkumar et al., 2005) 
Table 3: Freundlich isotherm results

\begin{tabular}{ccccc}
\hline Dye & Temp & \multicolumn{3}{c}{ statistical parameters/constants } \\
& ${ }^{0} \mathbf{C}$ & $\mathbf{r}^{\mathbf{2}}$ & $\mathbf{K}_{\mathbf{f}}$ & $\mathbf{n}$ \\
& & & & \\
$\mathbf{4 G}$ & $\mathbf{3 0}$ & 0.9963 & 1.2711 & 2.0303 \\
& $\mathbf{4 0}$ & 0.9900 & 1.2996 & 2.0735 \\
& $\mathbf{5 0}$ & 0.9984 & 1.3322 & 2.1502 \\
& $\mathbf{6 0}$ & 0.9970 & 1.3586 & 2.1940 \\
& & & & \\
\hline
\end{tabular}

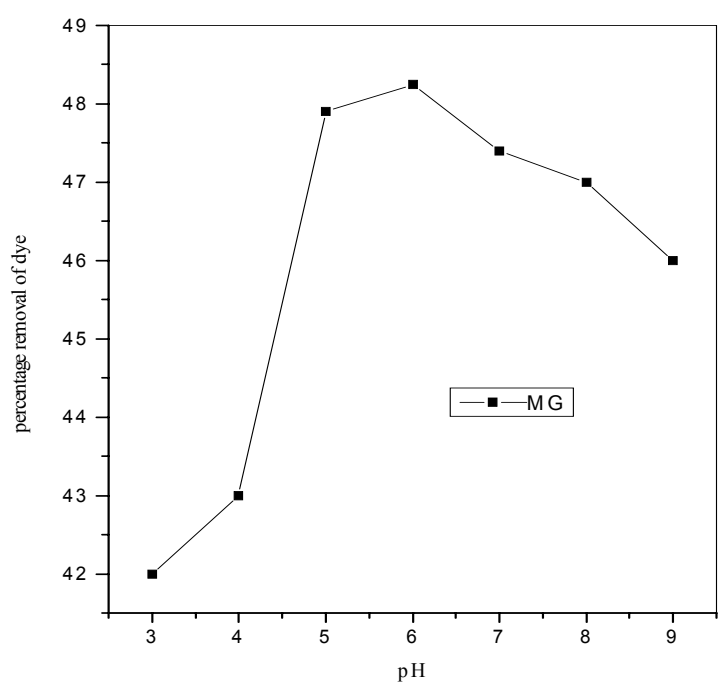

Figure 3-Effect of $\mathrm{pH}$ on the removal of MG by PDC

The Freundlich equation was also employed for the adsorption of Malachite green (MG) dye on the adsorbent. The Freundlich isotherm is represented by the following equation

$$
\log \mathrm{Q}_{\mathrm{e}}=\log \mathrm{K}_{\mathrm{f}}+1 / \mathrm{n} \log \mathrm{C}_{\mathrm{e}}
$$

Where $\mathrm{Q}_{\mathrm{e}}$ is the amount of Malachite green (MG) dye adsorbed $(\mathrm{mg} / \mathrm{g}), \mathrm{C}_{\mathrm{e}}$ is the equilibrium concentration of dye in solution $(\mathrm{mg} / \mathrm{L})$ and $\mathrm{K}_{\mathrm{f}}$ and $\mathrm{n}$ are constants incorporating all factors affecting the adsorption capacity and intensity of adsorption, respectively. Linear plot of $\log Q_{e}$ versus $\log C_{e}$ shows that the adsorption of Malachite green (MG) dye follows the Freundlich isotherm. Values of $\mathrm{K}_{\mathrm{f}}$ and $\mathrm{n}$ were found and given in the Table 3, shows the increase of negative charge due to the presence of $-\mathrm{COOH},-\mathrm{SO}_{3} \mathrm{H},-\mathrm{OH}$ and $-\mathrm{CHO}$ groups on the surface of the adsorbent that enhances the electrostatic force like vanderwaal's between the carbon surface and dye ion, which increases the adsorption of MG. The values clearly show that dominance in adsorption capacity. The intensity of adsorption is an indicative the bond energies between dye and adsorbent and the possibility of slight chemisorption rather than physisorption. The possibility of multilayer adsorption of dye through the percolation process cannot be ruled out, because the value of $\mathrm{n}$ is greater than one (Namasivayam et al., 1996). 
Table 4: Dimensionless Separation factor $\left(\mathrm{R}_{\mathrm{L}}\right)$

\begin{tabular}{ccccc}
\hline \multicolumn{5}{c}{ Temperature $\left({ }^{\circ} \mathbf{C}\right)$} \\
{$[\mathrm{D}]_{0}$} & $\mathbf{3 0}$ & $\mathbf{4 0}$ & $\mathbf{5 0}$ & $\mathbf{6 0}$ \\
$(\mathbf{m g} / \mathrm{L})$ & \multicolumn{5}{c}{ MG adsorption } \\
\multicolumn{5}{c}{ 4: Dimensionless Separation factor $\left(\mathrm{R}_{\mathrm{L}}\right)$} \\
$\mathbf{5}$ & 0.5882 & 0.5555 & 0.5617 & 0.5494 \\
$\mathbf{1 0}$ & 0.4166 & 0.3846 & 0.3906 & 0.3773 \\
$\mathbf{1 5}$ & 0.3225 & 0.2941 & 0.2994 & 0.2881 \\
$\mathbf{2 0}$ & 0.2631 & 0.2380 & 0.2427 & 0.2325 \\
$\mathbf{2 5}$ & 0.2222 & 0.2000 & 0.2040 & 0.1951 \\
$\mathbf{3 0}$ & 0.1923 & 0.1724 & 0.1760 & 0.1680 \\
\hline
\end{tabular}

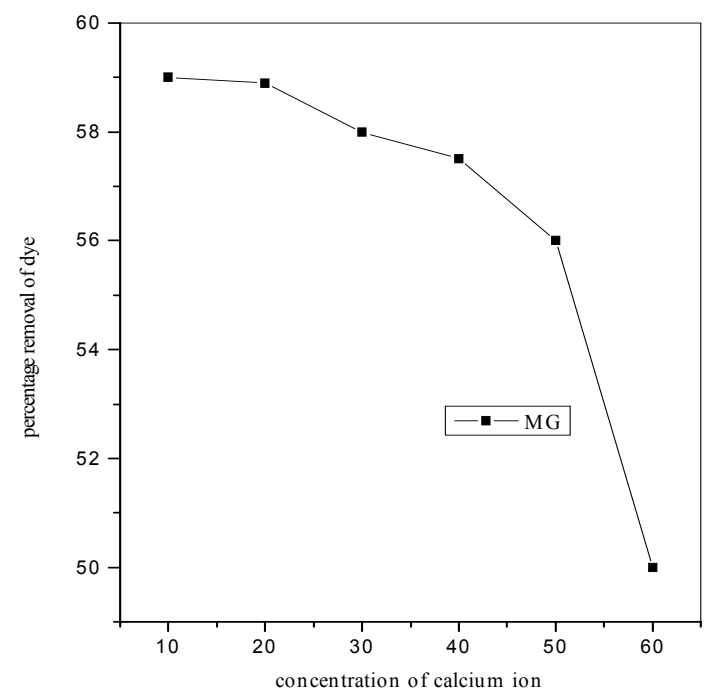

Figure. 4-Effect of calcium ion on the adsorption of dye by PDC

\section{Kinetics of adsorption}

Kinetics of sorption describes the solute uptake rate, which in turn governs the residence time of sorption reaction. It is one of the important characteristics in defining the efficiency of sorption. In the present study, the kinetics of the dye removal was carried out to understand the behaviour of this low cost carbon adsorbent. The adsorption of dye from an aqueous solution follows reversible first order kinetics, when a single species is considered on a heterogeneous surface. The heterogeneous equilibrium between the dye solution and the activated carbon have expressed as

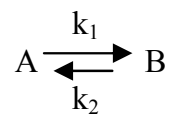

Where $\mathrm{k}_{1}$ is the forward rate constant and $\mathrm{k}_{2}$ is the backward rate constant. A represents dyes remaining in the aqueous solution and $\mathrm{B}$ represents dyes adsorbed on the surface of activated carbon. The rate constants were calculated as earlier. The data is furnished in Table 6. It is evident that the forward rate constant is much higher than the backward rate constant suggesting that the rate of adsorption is clearly dominant. At equilibrium, the rate is the ratio of the concentration of adsorbate in adsorbent and concentration of adsorbate in aqueous solution given by $\mathrm{K}_{0}$. The calculated values are presented in the Table 5 . The results indicates that $\mathrm{K}_{0}$ values decreases with increase in the concentration of the dye and increases with increase in temperature. 
Table 5 Equilibrium constant and thermodynamic parameters for the adsorption of dyes onto carbon

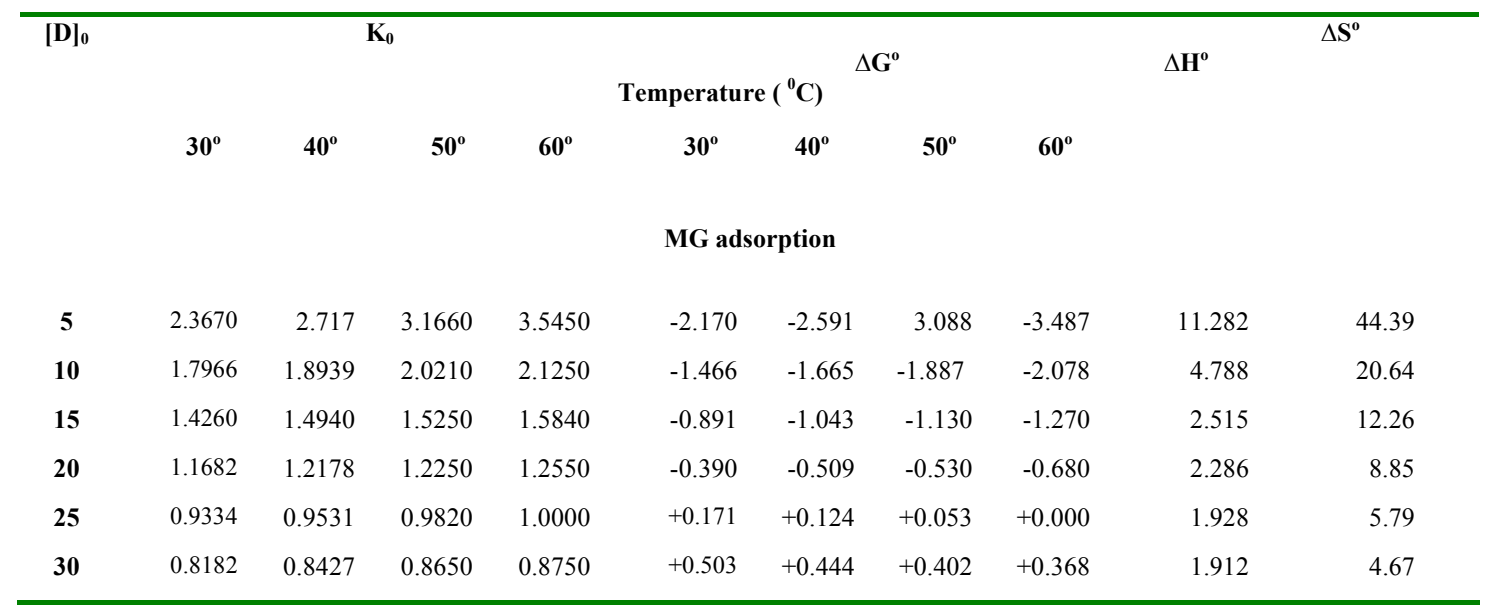

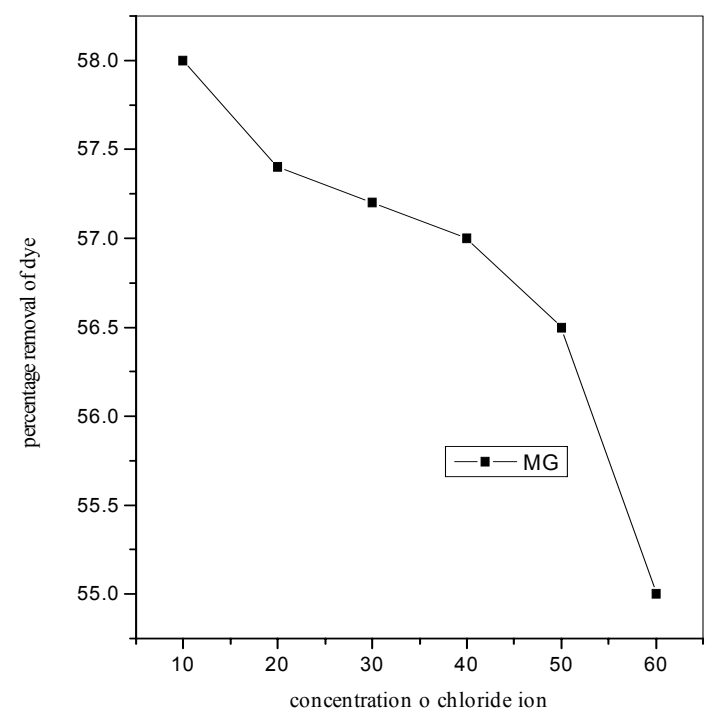

Figure.5-Effect of chloride ion on the removal of dye by PDC

The clear examination of the effect of dye concentrations on the rate constant $\mathrm{K}_{\mathrm{ad}}$ shown in Table. 6 helps to describe the mechanism of dye removal taking place .In cases of strict surface adsorption a variation of rate should be proportional to the first power of concentration. However, when pore diffusion limits the adsorption process, the relationship between initial dye concentration and rate of reaction will not be linear. It shows that pore diffusion limits the overall rate of dye adsorption (Sreedhar and Anirudhan., 1999; McKay and Poots., 1980)

The contact-time experimental results can be used to study the rate-limiting step in the adsorption process shown by Weber. Since the particles are vigorously agitated during the adsorption period, it is probably reasonable to assume that, rate is not limited by mass transfer from the bulk liquid to the particle external surface. One might then postulate that the rate-limiting step may be either film or intraparticle diffusion. As they act in series, the slower of the two will be the rate-determining step. The rate constant for intraparticle diffusion is obtained using the equation

$\mathrm{Q}=\mathrm{K}_{\mathrm{p}} \mathrm{t}^{1 / 2}$

Here, $K_{p}(\mathrm{mg} / \mathrm{g} / \mathrm{min})$ is the intraparticle diffusion rate constant. The nature of the plots suggests that the initial curved portion is attributed to the film or boundary layer diffusion effect and the subsequent linear portion to the intraparticle diffusion effect. It also depicts that the intraparticle diffusion is the slow and the rate-determining step. The $\mathrm{K}_{\mathrm{p}}$ values were obtained from the slope of the linear portions of the curves at each dye concentration (Table 7). The $K_{p}$ values increased with increase in the dye concentration, which reveals that the rate of adsorption is governed by the diffusion of adsorbed dye within the pores of the adsorbent (MaKay et al., 1982; [Weber., 1967). 
Table 6: Rate constants for the adsorption of dye $\left(10^{3} \mathrm{k}_{\mathrm{ad}}, \min ^{-1}\right)$ and the constants for forward $\left(10^{3} \mathrm{k}_{1}, \min ^{-1}\right)$ and reverse $\left(10^{3} \mathrm{k}_{2}, \mathrm{~min}^{-1}\right)$ process

\begin{tabular}{|c|c|c|c|c|c|c|c|c|c|c|c|c|}
\hline \multirow{3}{*}[\mathrm{D}]{$_{0}$} & \multicolumn{10}{|c|}{ Temperature $\left({ }^{0} \mathrm{C}\right)$} & & \\
\hline & \multicolumn{3}{|c|}{$\mathbf{k}_{\mathrm{ad}}$} & & \multicolumn{2}{|c|}{30} & \multicolumn{2}{|c|}{40} & \multicolumn{2}{|c|}{50} & \multicolumn{2}{|c|}{60} \\
\hline & $30^{\circ}$ & $40^{\circ}$ & $50^{\circ}$ & $60^{\circ}$ & $\mathrm{K}_{1}$ & $\mathbf{k}_{2}$ & $k_{1}$ & $\mathbf{k}_{2}$ & $\mathbf{k}_{1}$ & $\mathbf{k}_{2}$ & $\mathbf{k}_{1}$ & $\mathbf{k}_{2}$ \\
\hline \multicolumn{13}{|c|}{ MG adsorption } \\
\hline 5 & 16.950 & 14.467 & 15.402 & 16.121 & 11.91 & 5.044 & 10.58 & 3.890 & 11.70 & 3.701 & 12.57 & 3.550 \\
\hline 10 & 6.909 & 8.659 & 9.073 & 9.212 & 4.43 & 2.476 & 5.94 & 3.138 & 5.79 & 2.864 & 6.26 & 2.952 \\
\hline 15 & 6.909 & 7.945 & 8.083 & 4.606 & 4.05 & 2.855 & 4.76 & 3.188 & 4.88 & 3.206 & 2.76 & 1.844 \\
\hline 20 & 6.448 & 6.448 & 6.909 & 4.606 & 3.46 & 2.981 & 3.53 & 2.914 & 3.79 & 3.112 & 2.02 & 2.047 \\
\hline 25 & 6.218 & 5.941 & 4.606 & 6.909 & 3.01 & 3.216 & 2.70 & 3.046 & 2.28 & 2.323 & 3.45 & 3.455 \\
\hline 30 & 5.987 & 5.757 & 5.987 & 6.909 & 2.69 & 3.293 & 2.63 & 3.206 & 3.78 & 3.206 & 3.21 & 3.695 \\
\hline
\end{tabular}

\section{Effect of temperature}

The adsorption capacity of the carbon increased with increase in the temperature of the system from $30^{\circ}-60^{\circ} \mathrm{C}$. Thermodynamic parameters such as change in free energy $\left(\Delta \mathrm{G}^{\circ}\right) \mathrm{kJ} / \mathrm{mol}$, enthalpy $\left(\Delta \mathrm{H}^{\circ}\right) \mathrm{kJ} / \mathrm{mol}$ and entropy $\left(\Delta \mathrm{S}^{\circ}\right) \mathrm{J} / \mathrm{mol}$ were determined by using the following equations (Kocke and Hemphill., 1981)

$$
\begin{aligned}
& \mathrm{K}_{0}=\mathrm{C}_{\text {solid }} / \mathrm{C}_{\text {liquid }} \ldots \ldots \ldots(3) \\
& \Delta \mathrm{G}^{\circ}=-\mathrm{RT} \ln \mathrm{K}_{\mathrm{O}} \ldots \ldots . .(4) \\
& \operatorname{IogK}_{0}=\Delta \mathrm{S}^{\circ} /(2.303 \mathrm{RT})-\Delta \mathrm{H}^{\circ} /(2.303 \mathrm{RT})
\end{aligned}
$$

Where $\mathrm{Ko}$ is the equilibrium constant, $\mathrm{C}_{\text {solid }}$ is the solid phase concentration at equilibrium $(\mathrm{mg} / \mathrm{L})$, $\mathrm{C}_{\text {liquid }}$ is the liquid phase concentration at equilibrium $(\mathrm{mg} / \mathrm{L}), \mathrm{T}$ is the temperature in Kelvin and $\mathrm{R}$ is the gas constant. The $\Delta \mathrm{H}^{\circ}$ and $\Delta \mathrm{S}^{\circ}$ values obtained from the slope and intercept of Van't Hoff plots are presented in Table 5. The values are with in the range of 1 to $93 \mathrm{KJ} / \mathrm{mol}$ and indicates the favourability of physisorption. From the order one could say that physisorption is more favourable for MG. The positive values of $\Delta \mathrm{H}^{\circ}$ show the endothermic nature of adsorption and also indicates the possibility of physical adsorption. Since in the case of physical adsorption, while increasing the temperature of the system, the extent of dye adsorption increases, this rules out the possibility of chemisorption. However, the very low $\Delta \mathrm{H}^{\circ}$ value depicts that the dye is physisorbed onto adsorbent (Sivaraj et al., 2001; Khattri and Singh., 1999)

The negative values of $\Delta \mathrm{G}^{\circ}$ (Table 5) shows that adsorption is highly favourable for $\mathrm{MG}$, it indicates that the dye adsorption was spontaneous. The positive values of $\Delta \mathrm{S}^{\circ}$ (Table 5) shows the increased disorder and randomness at the solid solution interface during the adsorption of dye on the adsorbent (PDC). The adsorbed water molecules, which was displaced by the adsorbate species, gain more translational entropy than is lost by the adsorbate molecules, thus allowing the prevalence of randomness in the system. Enhancement of adsorption capacity of PDC at higher temperatures may be attributed to the enlargement of pore size and/or activation of the adsorbent surface (Namasivayam and Yamuna.. 1995)

\section{Effect of pH}

The experiments carried out at different $\mathrm{pH}$ shows that there was a change in the percent removal of dye 0over the entire $\mathrm{pH}$ range of 3 to 9 shown in the Figure 5. This indicate the strong force of interaction between the dye and the activated carbon that, either $\mathrm{H}^{+}$or $\mathrm{OH}$ - ions could influence the adsorption capacity. Here the interaction is larger at $\mathrm{pH} 6$, the competition of acidic $\mathrm{H}^{+}$ion with dye cation for the sorption sites increased at this $\mathrm{pH}$ value is due to the presence of ionic $\mathrm{COOH}, \mathrm{SO}_{3} \mathrm{H}$ and $\mathrm{OH}$. The adsorption of dye on the activated carbon does involve ion exchange mechanism. Due to this mechanism there should be an influence on the dye adsorption while varying the $\mathrm{pH}$. This observation is in line with the Langmuir and Freundlich isotherms. The positive $\Delta \mathrm{H}^{\circ}$ values obtained, which indicates irreversible adsorption probably due to polar interaction (Gong et al ., 2005)

\section{Desorption studies}

Desorption studies help to elucidate the nature of adsorption and recycling of the spent adsorbent and the dye. If the adsorbed dye can be desorbed using neutral $\mathrm{pH}$ water, then the attachment of the dye of the adsorbent is by weak bonds. If sulphuric acid or alkaline water desorb the dye, then the adsorption 
is by ion exchange. If organic acids, like acetic acid can desorb the dye, then the dye is held by the adsorbent through chemisorption. The effect of various reagents used for desorption studies shows that hydrochloric acid is a better reagent for desorption, because one could get more than $90 \%$ removal of adsorbed dye. The reversibility of adsorbed dye in mineral acid or base is in agreement with the $\mathrm{pH}$ dependent results. The desorption of dye by mineral acids and alkaline medium indicates that the dye was adsorbed onto the activated carbon by physisorption mechanisms (Sreedhar and Anirudhan., 1999).

\section{Effect of other ions}

The effect of other ions like $\mathrm{Ca}^{2+}$ and $\mathrm{Cl}^{-}$on the adsorption process were studied at different concentrations. The ions were added in a concentration of $20 \mathrm{mg} / \mathrm{L}$ of dye solutions and the contents were agitated for $60 \mathrm{~min}$ at $30^{\circ} \mathrm{C}$. The results are shown in the Figure 5 and 6 and reveals that low concentration of $\mathrm{Cl}^{-}$does not affect the available sites of adsorbent through competitive adsorption. When the concentration of $\mathrm{Ca}^{2+}$ increase the interference of these ions at available surface sites of the sorbent through competitive adsorption increases that decreases the percentage adsorption. The interference was more in the presence of $\mathrm{Ca}^{2+}$ compared with $\mathrm{Cl}^{-}$ion. This is so because ions with smaller hydrated radii decrease the swelling pressure with in the sorbent and increase the affinity of the sorbent for such ions (Krishna and Bhattacharriya., 2002; Sreedharn and Anirudhan., 1999).

\section{Conclusions}

The experimental data correlated reasonably well with the Langmuir and Freundlich adsorption isotherms and the respective isotherm parameters were calculated. The amount of dye adsorbed increases with the increase in $\mathrm{pH}$ of the medium. The amount of the Malachite green adsorbed decreases with increasing the ionic strength and increase with the increase in temperature. The dimensionless separation factor shows that the activated carbon can be used for the removal of Malachite green from aqueous solution. The values of $\Delta \mathrm{H}^{\circ}, \Delta \mathrm{S}^{\circ}$ and $\Delta \mathrm{G}^{\circ}$ shows that employed carbon in this work has a considerable potential as an adsorbent for the removal of Malachite green

Acknowledgement: The authors sincerely acknowledge Mrs. Mala Arivoli, The Principal, M.R.Government Arts College, Mannargudi and The Director of Collegiate Education, Chennai for carrying out this research work successfully.

\section{REFERENCES}

Aravind K Singh and Prem N Tiwari (2003), Removal basic dye from industrial wastewater by adsorbent, Indian J Chem Technol, 10, 215.
Freundlich H (1906), Adsorption in solutions, Phys Chemie, 57, 384.

Khattri S D and Singh M K (1999), Sorption, recovery of metal ions from aqueous solution using humus, Indian J Chem Technol, 3, 114.

Kocke W R and Hemphill L H (1981), Adsorption kinetics of activated carbon Water Res, 15, 275 .

Krishna D G and Bhattacharyya G (2002), Adsorption of methylene blue on kaolinite, Appl Clay Sci, 20, 295.

Langmuir I (1918), Adsorption of gases on plane surfaces of glass, mica and platinum, J Amer Chem Soc, 40, 1361.

McKay G, Blair H S and Gardner J R (1982), The adsorption of dyes onto chitin in fixed bed columns and batch adsorbers, J Appl Sci, 27, 3042 .

McKay G and Poots V J P (1980), Kinetics and diffusion process in colour removal from effulent using wood as an adsorbent, $J$ Chem Tech Biotechnol, 30, 279.

Namasivayam C, Muniasamy N, Gayatri K, Rani $\mathrm{M}$ and Ranganathan K (1996), Removal of dyes from aqueous solution by cellulosic waste orange peel, Biores Technol, 57, 37.

Namasivayam C and Yamuna R T (1995), Adsorption of direct red by biogas residual slurry, Environ Pollut, 89, 1.

Renmin Gong, Yingzhi Sun, Jian Chen, Huijun Liu, Chao yang (2005), Effect of chemical modification on dye adsorption capacity of peanut hull, Dyes and Pigments, 67, 179.

Sekaran G, Shanmugasundaram K A, Mariappan M and Raghavan K V (1995), Adsorption of dyes by buffing dust of leather industry, Indian $J$ Chem Technol, 2, 311.

Selvarani K (2000), Studies on Low cost Adsorbents for the removal of Organic and Inorganics from Water, $P h D$., Thesis, Regional Engineering College, Tiruchirapalli.

Senthikumar S, Varatharajan P R, Porkodi K, Subburaam C V (2005), Adsorption of methylene blue carbon onto jute fibre carbon, $J$ Colloid Interface Sci, 284, 79.

Sivaraj R, Namasivayam C and Kadirvelu K (2001), Orange peel as an adsorbent in the 
removal of acid violet from aqueous solution, Waste Management, 21, 105.

Sreedhar M K and Anuirudhan T S (1999), Mercury (II) adsorption of desorption characteristics of coconut husk based carbonKinetics and self diffusion, Indian J Environ Protect, 19, 8.
Vadivelan V, Vasanthkumar K (2005),

Equilibrium, kinetics, mechanism and process design for the sorption of methylene blue onto rice husk, J Colloid Interface Sci, 286, 91.

Weber W J (1967), Principle and Application of Water Chemistry, edited by Faust $S D$ and Hunter J V Wiley, New York. 